\title{
Ilkvepiamojo budezonido vaidmuo gydant astmą: farmakologinių tyrimų pamokos
}

\author{
Laimutè Vaidelienè \\ LSMU MA Vaikų liguc klinika
}

Reikšminiai žodžiai: nuolatinè astma, ¿kvepiamieji gliukokortikoidai, budezonidas, sudètinis gydymas, gydymo saugumas. Santrauka. [kvepiamieji gliukokortikoidai ([GK) yra pirmaeiliai ilgalaikio astmos gydymo vaistai. Naujos ilgalaikio astmos gydymo budezonidu studijos suteike daug idomios informacijos, papildančios astmos gydymo rekomendacijas. Trejų metu trukmès dvigubai aklo START (angl. inhaled Steroid Treatment As Regular Therapy) tyrimo rezultatai parode, kad anksti pradėtas gydymas ỉkvepiamuoju budezonidu sumažina kvėpavimo sutrikimus ir būsimų sunkių paūmėjimų tikimybę 44 proc. suaugusiujų ir vaikų, sergančių naujai diagnozuota bei lGK iki tol negydyta astma. Deja, ankstyvo gydymo lGK teigiama įtaka ilgalaikiams kvėpavimo funkcijos pokyčiams nebuvo įrodyta. Panašūs duomenys gauti ir CAMP (angl. Childhood Asthma Management Program) studijoje, kuri patvirtino, kad gydymas IGK neveikia natūralios astmos eigos. Vis dèlto CAMP studijos indèlis i astmos gydymo rekomendacijas labai svarbus, nes joje patvirtinta nuolatinio gydymo |GK būtinybè, ne norint paveikti natūralią ligos eigą, o siekiant pagerinti astmos kontrolę.

Dažnas astma sergantis pacientas vengia vartoti ĮGK ilgą laiką. Svarbiausia priežastis - nepageidaujamo poveikio baimè. Todèl siekiama minimizuoti nepageidaujamus reiškinius ir padaryti astmos gydymą dar patogesni. START studija patvirtino budezonido efektyvumą ir saugumą vartojant ji vieną kartą per parą, o OPTIMA (angl. Oxis and Pulmicort Turbuhaler in the Management of Asthma) ir FACET (angl. Formoterol And Corticosteroids Establishing Therapy) studijos irode sudètinio gydymo efektyvumą bei saugumą gydant vidutinio sunkumo ir sunkią astmą.

Visi kartu šie tyrimai pagrindžia kasdienės IGK terapijos efektyvumą ir saugumą gydant nuolatinės eigos lengvą ar vidutinio sunkumo astmą, palaiko ankstyvo gydymo [GK naudą ir pateikia sudetinio gydymo indikacijas.

Nepaisant daugybès sutarimų ir rekomendacijų, astma kontroliuojama vis dar nepakankamai, o pacientai dažnai vengia vartoti vaistus ilgą laiką. Visų pirma dèl to, kad prastai išmano ligos patogenezę ir vaistų veikimo mechanizmus, baimindamiesi nepageidaujamų reiškinių, mažina vaistų kiekį, dozes ar gydymo trukmę. Todèl gydymo schemos, vaistų efektyvumo vertinimo kriterijai nuolat tobulinami, ieškoma saugesnių gydymo metodų.

Pirmosiose tarptautinèse astmos diagnostikos ir gydymo rekomendacijose pagrindinis gydymo parinkimo kriterijus buvo ligos sunkumas. Nors astmos sunkumas išlieka svarbiausias ligos intensyvumo rodiklis, naujausios GINA (angl. Global Initiative for Asthma) ir Naciona- linès astmos mokymo ir profilaktikos programos (angl. National Asthma Education and Prevention Program) rekomendacijos akcentuoja, kad astma yra kintama liga ir jos gydymas priklauso ne tik nuo ligos sunkumo, bet ir nuo jos kontrolès bei atsako ị vaistus $[1,2]$. Gydant astmą, remtis tik ligos sunkumu yra neracionalu, mat dažni bei sunkūs paūmèjimai galimi ir sergant lengva astma. Taigi nekontroliuojama gali būti bet kokio sunkumo astma. Tyrimai rodo, kad pusė visų nekontroliuojamos ligos atvejų nustatoma pacientams, sergantiems epizodine (35 proc.) ir lengva nuolatine (26 proc.) astma [3].

Keičiantis požiūriui, ịvardijamas ir naujas gydymo tikslas - mažinant kvėpavimo sutrikimus ir riziką, pa- 
siekti ir išlaikyti ligos kontrolę. I kvėpavimo sutrikimų sąvoką ieina ligos simptomų dažnumas bei intensyvumas ir kvėpavimo funkcijos pokyčiai. Rizika apima paūmẻjimų tikimybę, vaistų nepageidaujamą poveikị bei negrižtamus organizmo pokyčius: plaučių funkcijos blogejjimą, vaikų plaučių augimo sutrikimą.

Akivaizdu, kad šiuos tikslus galima pasiekti tik kontroliuojant kvėpavimo takų uždegimą. İkvepiamieji gliukokortikoidai (IGK) vieninteliai slopina daugybę uždegimo grandžių, todèl yra pirmaeiliai vaistai nuolatinei astmai gydyti. Jie gali būti vartojami vieni arba derinami su ilgo veikimo beta 2 agonistais (IVBA). Budezonidas (BUD) vienas dažniausiai astmai gydyti vartojamų IGK. Atlikta nemažai budezonido studijų, kurios padeda įvertinti İGK vietą gydant astmą ir prisideda prie bendro supratimo apie astmos kontrolę [6, 7, 8, 9, 10, 11, 12].

\section{ANKSTYVAS ASTMOS GYDYMAS IKVEPIAMAISIAIS GLIUKOKORTIKOIDAIS}

Keletas seniau atliktų studijų parodè, kad, anksti pradèjus astmą gydyti IGK, galima tikètis geresnių rezultatų $[13,14]$. Tačiau minètose studijose daugiausia dalyvavo pacientai, kurių astma jau seniai diagnozuota. START (angl. Inhaled Steroid Treatment As Regular Therapy) buvo pirmoji ilgalaikè atsitiktinių imčių dvigubai akla studija, kurioje ankstyvas gydymas IGK skirtas per pirmuosius 2 metus nuo astmos diagnozès nustatymo [6, 7]. Tyrime dalyvavo 7240 5-66 metų amžiaus pacientų, kurių astma iki tol nebuvo gydyta IGK. Kartu su iprastiniu astmos gydymu tiriamiesiems skirta budezonido vieną kartą per parą arba placebo.

START trejų metu dvigubai aklos gydymo fazès duomenys rodo, kad anksti pradètas astmos gydymas budezonidu statistiškai reikšmingai sumažina paūmèjimų riziką iki tol IGK negydytiems pacientams. 3 metus budezonidu gydytiems suaugusiems ligoniams rečiau prireikè sisteminių gliukokortikoidų (GK), o laikotarpis iki pirmojo sisteminių GK kurso buvo statistiškai reikšmingai ilgesnis nei placebo grupèje ( $\mathrm{p}<0,0001)$. BUD grupèje buvo daugiau dienų be astmos simptomų, rečiau reikejjo gydytojo pagalbos, pacientai mažiau dienuc praleido stacionare $(\mathrm{p}<0,001)$.

5-10 metuc vaikų grupeje nustatyti tokie pat rezultatai kaip ir suaugusiųjų: gydymas budezonidu, lyginant su placebu, statistiškai reikšmingai padidino dienų be astmos simptomų skaičių, 50 proc. sumažino stacionare praleistų dienų skaičių, 34 proc. sumažino skubiosios pagalbos vizitu. Kvėpavimo funkcija BUD grupejje po 3 metu gydymo buvo statistiškai reikšmingai geresnè, o FEV 1 blogejjimas statistiškai reikšmingai mažesnis nei placebo grupèje ( $\mathrm{p}<0,0001)$.

Po pradinio 3 metu dvigubai aklo gydymo periodo ejo 2 metuc atviras gydymo periodas: placebo grupès tiriamiesiems taip pat skirta budezonido, tik jau praejus 3-5 metams nuo ligos nustatymo, t. y. vèlesniu astmos gydymo etapu.

Bendri 5 metu STRAT studijos duomenys rodo, kad anksti budezonidu pradètų gydyti pacientų grupejje astmos simptomų bei sunkių astmos paūmèjimų buvo mažiau, bet BUD skyrus po 3 metu placebo grupès tiriamiesiems statistiškai reikšmingi skirtumai tarp grupių išnyko. Kvèpavimo funkcija $\left(\mathrm{FEV}_{1}\right)$ po 5 metuc taip pat patikimai nesiskyrè. Vaikų ir paauglių grupeje ankstyvas BUD vartojimas nesumažino ir bronchų išplètimo mèginio įtakos $\mathrm{FEV}_{1}$ kitimams. Taip START tyrimas įrodè, kad ankstyvas gydymas IGK neabejotinai pagerina astmos kontrolę, bet neturi įtakos kvejpavimo funkcijos pokyčiams bei natūraliai ligos eigai.

\section{ILGALAIKIO ASTMOS GYDYMO İGK REZULTATAI}

Astmą gydantiems specialistams jau nereikia aiškinti, kad gydymas IGK turi būti nuolatinis, tačiau pacientai neretai "patobulina“ paskirtą gydymą ir visus vaistus (taip pat ir IGK) vartoja tik būklei pablogèjus.

2000-2003 metais atlikto IMPACT (angl. IMProving Asthma Control Trial) budezonido tyrimo, kuriame dalyvavo 225 suauge pacientai, rezultatai aiškiai įrodo nuolatinio gydymo İGK naudą gerinant astmos kontrolę, mažinant uždegimą ir bronchų hiperreaktyvumą [4, 23].

2000 metais publikuoti CAMP (angl. the Childhood Asthma Management Program) tyrimo duomenys taip pat puikiai atskleidžia ilgalaikio gydymo IGK efektyvumą ir naudą 5-12 metų vaikams [15]. Nuolatine astma sergantys pacientai buvo gydomi mažomis/vidutinėmis dozėmis budezonido arba nedokromiliu du kartus per dieną, arba placebo. Gydymas truko 4-6 metus. BUD gydytų vaiku grupejje, lyginant su placebu, astmos simptomų, skubių gydytojo iškvietimų, stacionare praleistų dienų nustatyta daug mažiau, mažesnis buvo ir salbutamolio bei geriamojo prednizolono poreikis $(\mathrm{p}<0,001)$. Kaip ir START studijoje, budezonidas neturejjo reikšmingos ittakos kvejpavimo funkcijos $\left(\mathrm{FEV}_{1}\right)$ pokyčiams bronchų išplètimo méginio metu. Tačiau spirometrijos rodikliai $\left(\mathrm{FEV}_{1}\right)$ BUD gydytu vaiku grupèje pagerejjo jau po 2 mèn. nuo gydymo pradžios ir gydymo periodo pabaigoje buvo statistiškai reikšmingai geresni nei placebo grupejje $(\mathrm{p}=0,02)$. Tokių skirtumų nenustatyta nedokromiliu gydytų vaiku grupeje. Bronchų reaktyvumas gydant BUD nuolat mažèjo viso gydymo metu ir išliko mažesnis nei placebo grupejje dar vidutiniškai 2-3 mènesius po gydymo nutraukimo.

CAMP studija neparemia teiginio, kad gydymas IGK gali paveikti natūralų ligos progresavimą, tačiau neabejotinai įrodo ilgalaikio gydymo IGK efektyvumą kontroliuojant astmą ir gerinant gyvenimo kokybę. Studija patvirtina nuolatinio gydymo IGK būtinybę ne norint keisti natūralią ligos eigą, o siekiant pagerinti astmos kontrolę.

\section{PATOGAUS IR SAUGAUS İGK VARTOJIMO PAIEŠKOS}

Nepaisant daugybės įrodymų, kad ilgalaikiu astmos gydymu IGK kvėpavimo takų uždegimas kontroliuojamas 
efektyviausiai, dažnas pacientas vengia vartoti İGK ilgą laiką. Dažniausios priežastys: nepageidaujamų reiškinių baimè bei lètesnis, ne toks kaip bronchus plečiančių vaistų, IGK poveikis [16]. Abi šios priežastys verčia ieškoti saugesniu bei patogesnių gydymo metodų.

Gydymas IGK vieną kartą per parą daro astmos gydymą patogesni ir didina tikimybę, kad pacientai tvarkingiau vartos vaistus. Pastarųjų 10 metų tyrimai rodo, kad dèl savo savybių budezonidas gali būti vartojamas 1 kartą per parą, mat jis kvėpavimo takų audiniu ląstelèse sudaro laikinus riebalų rūgščių esterius, formuoja neaktyvaus vaisto sankaupas ląstelèje, iš kuriụ vaistas gali išsiskirti palengva [18].

Vienas iš START tyrimo tikslų buvo ịvertinti budezonido, vartojamo vieną kartą per parą, efektyvumą ir saugumą [6]. 5 metų tyrimas parodè, kad vieną kartą per parą vartojamas BUD (<11 m. vaikams - $200 \mu \mathrm{g}$, vyresniems ir suaugusiesiems - $400 \mu \mathrm{g}$ ) buvo gana efektyvus gydant lengvą nuolatinę astmą. Toks gydymo metodas ne tik pagerino ligos kontrolę, lyginant su placebo grupe, bet ir sumažino papildomų vaistu poreikį.

Šie rezultatai patvirtina 2004 metais atliktų 10-ties studijų, lyginusių du kartus ir vieną kartą per parą vartojamo BUD efektyvumą, metaanalizès duomenis [16]. Lengva ar vidutinio sunkumo nuolatine astma sergantys 1922 vaikai ir suaugusieji buvo gydomi vieną arba du kartus per parą ta pačia BUD paros doze (pagal poreiki nuo 200 iki $800 \mu \mathrm{g}$ ). Vieną ar du kartus per parą vartojusių BUD pacientų grupèse nebuvo nustatyta jokių statistiškai reikšmingų astmos kontrolès skirtumų: nesiskyrè klinikinių simptomų dažnumas, paūmèjimų skaičius, sunkių astmos paūmèjimų, dèl kurių negalima tęsti studijos, skaičius. Dvi metaanalizèje vertintos studijos tyrẻ bronchų reaktyvumo kitimus, vartojant BUD vieną ar du kartus per parą. Jų duomenimis, bronchų hiperreaktyvumo sumažejimas gydant abiem metodais buvo vienodas. Visi šie duomenys pagrindžia galimybę budezonidą vartoti ta pačia paros doze, bet mažesniu dažnumu sergant lengva ar vidutinio sunkumo nuolatine astma. Šių rekomendacijų nereikètų aklai taikyti sunkia astma sergantiems pacientams, su kuriais tyrimų nebuvo atlikta. Vis dèlto apie 80 proc. astmos ligonių, kurių liga yra lengvos ar vidutinio sunkumo eigos, galima gerai kontroliuoti astmą vieną kartą per parą vartojamu BUD.

Tačiau buvo būtina išsiaiškinti, ar $1 \mathrm{k} . / \mathrm{d}$. vartojama dvigubai didesnè BUD dozè yra tokia pat saugi, kaip ir mažesnès dozès, vartojamos $2 \mathrm{k} . / \mathrm{d}$.

2000 metais švedai L. Thorsson ir A. Kallen lygino ikvepiamojo budezonido poveiki hipotalamo (pogumburio)-hipofizès-antinksčių (angl. hypothalamicpituitary-adrenal axis, HPA) sistemai skiriant jo po 400 $\mu \mathrm{g} 2 \mathrm{k} . / \mathrm{d}$. arba $800 \mu \mathrm{g} 1 \mathrm{k.} / \mathrm{d}$. [19]. Be to, buvo žiūrèta, ar skiriasi sisteminis BUD poveikis skiriant ji ivairiu paros metu: 1 k./d. tik ryte arba tik vakare. Tyrejjai nustatė, kad visose BUD gydytu pacientų grupèse kortizolio kiekis kraujo serume gydymo laikotarpiu buvo patikimai mažesnis, lyginant su placebo grupe. Tačiau jis vertintas, kaip kliniškai nereikšmingas. Tokia išvada padaryta remiantis ankstesnių studijų su BUD duomenimis. Nustatyta, kad $3200 \mu \mathrm{g}$ BUD paros dozė slopina antinksčių kortizolio gamybą taip pat kaip 10 dienų geriamojo prednizolono kursas, o ši prednizolono dozė laikoma saugia, nesukeliančia kliniškai reikšmingo nepageidaujamo poveikio.

Pastebėta ryškesnẻ antinksčių slopinimo tendencija vartojant BUD 1 k./d. vakare, tačiau skirtumai nebuvo reikšmingi nei statistiškai, nei kliniškai. Todèl daroma išvada, kad vakarinis BUD vartojimas gali būti rekomenduojamas tiems pacientams, kurių astmos simptomai ryškesni nakties metu ar anksti ryte [19].

Studijose, kuriose dalyvauja vaikai, vertinant IGK saugumą, dėmesys ypač kreipiamas ị dažniausiai nurodomą IGK nepageidaujamą poveikị - sulètèjusị augimą $[4,6,7]$.

START tyrime BUD gydytų 5-10 metų vaikų ūgis nesiskyrè nuo placebo grupès vaikų [4, 20]. Vyresnių nei 11 metų vaikų, gydytų BUD, ūgis nuo placebo grupès atsiliko $1,34 \mathrm{~cm}$, ir šis atsilikimas ryškiausias buvo pirmaisiais gydymo IGK metais $(-0,58 \mathrm{~cm})$. CAMP tyrimo pabaigoje (po 4-6 metu gydymo) vaikų ūgio prieaugis taip pat buvo patikimai mažesnis BUD grupejje $(22,7 \mathrm{~cm})$, lyginant su placebo grupe $(23,8 \mathrm{~cm})$. Skirtumas buvo ryškiausias pirmaisiais gydymo BUD metais, o vèliau visose grupése augimo sparta buvo vienoda. Perspektyviosios studijos rodo, kad, nepaisant augimo sulètejjimo pirmuosius 3 gydymo IGK metus, galutinis suaugusiųjų ūgis (vidutiniškai po 9,2 metų) yra toks pat kaip ir placebo grupès [21].

Taigi, siekiant minimizuoti nepageidaujamus reiškinius ir padaryti gydymą dar patogesnį, START, CAMP ir kitos studijos patvirtino budezonido efektyvumą ir saugumą vartojant jị vieną kartą per parą.

\section{SUDĖTINIO GYDYMO VAIDMUO KONTROLIUOJANT ASTMA}

Nors daugumos pacientų astma gali būti kontroliuojama vartojant mažas ar vidutines IGK dozes, kai kuriems, sergantiems vidutinio sunkumo ar sunkios eigos astma, tokio gydymo nepakaks. Tokiais atvejais, siekiant išvengti nepageidaujamo IGK poveikio, rekomenduojama ne didinti İGK dozę, o derinti juos su ilgo veikimo beta 2 agonistais (IVBA), leukotrienų receptorių antagonistais ar teofilinais. Nuo 1994 metų vykdomos studijos aiškiai rodo, kad IGK ir IVBA derinys parnoksta didelemis dozèmis vartojamą IGK $[5,22]$.

OPTIMA (Oxis and Pulmicort Turbuhaler in the Management of Asthma) studija ivertino formoterolio (FT), pridedamo prie mažos budezonido dozès, efektyvumą vyresniems nei 12 metų pacientams. Metus trukęs tyrimas parodè, kad pacientams, iki tol negydytiems IGK, $100 \mu \mathrm{g}$ BUD ir 4,5 $\mu \mathrm{g}$ FT derinys $2 \mathrm{k} . / \mathrm{d}$. nèra efektyvesnis už $100 \mu \mathrm{g}$ BUD 2 k./d. Tuo tarpu pacientams, kurių astmos kontrolè buvo nepakankama gydant maža BUD doze, sudètinis gydymas sąlygojo geresnę ligos kontrolę. Taigi OPTIMA studija reko- 
menduoja pacientams, kurių astma iki tol negydyta IGK, gydymą pradèti nuo monoterapijos IGK, o jei liga blogai kontroliuojama mažomis IGK dozèmis, taikyti sudètini gydymą pridedant IVBA.

Kitoje sudetinio gydymo BUD ir FT studijoje FACET (angl. Formoterol And Corticosteroids Establishing Therapy) dalyvavo 852 suaugusieji, sergantys vidutinio sunkumo ir sunkia astma [4]. Irodyta, kad sudetinis gydymas BUD ir FT bei didesnè BUD dozè $(400 \mu \mathrm{g} 2$ k./d.) apsaugo nuo sunkių ligos paūmèjimų geriau nei monoterapija maža BUD doze $(100 \mu \mathrm{g} 2 \mathrm{k} . / \mathrm{d}$.).

OPTIMA ir FACET studijos apibrèžè nuolatine astma sergančiu pacientu populiaciją, kuriai sudètinis gydymas IGK ir IVBA galètų būti naudingas. Pacientams, iki tol negydytiems IGK, reikètų pradèti gydymą nuo monoterapijos IGK ir tik tada, kai astmai kontroliuoti jos nepakanka, rekomenduojama didinti IGK dozę arba skirti sudetini gydymą IGK ir IVBA.

Naujausios farmakologinès budezonido studijos papildo mūsų supratimą apie IGK vaidmeni gydant astmą. Visos kartu (START, CAMP, OPTIMA ir FACET) šios studijos pagrindžia astmos gydymo rekomendacijas, paremtas pakopinio gydymo principu. Patvirtintas nuolatinio gydymo IGK poreikis, ne norint paveikti natūralią ligos eigą, o siekiant pagerinti astmos kontrolę. Irodytas kasdienès IGK terapijos efektyvumas ir saugumas, ankstyvo gydymo IGK nauda gydant nuolatinès eigos lengvą ar vidutinio sunkumo astmą. Tyrimais pagrịstos sudètinio gydymo indikacijos. Taigi, budezonido tyrimai suteikia GINA ir kitoms astmos gydymo rekomendacijoms mokslinị pagrindą ir įrodo jų praktinę vertę.

\section{LITERATŪRA}

1. National Heard, Lung, Blood Institute (NHLBI). National Asthma Education and Prevention Program expert panel report 3: Guidelines for the diagnosis and management of asthma. Full Report 2007, NHLBI publication no. 08-4051, www.nhlbi.nih.gov/guidelines/asthma/asthgdln.pdf.

2. Global Initiative for Asthma (GINA). Global strategy for asthma management and prevention. Updated 2007, www.ginasthma.com .

3. Desfougeres JL, Sohier B, Freedman D, et al. Perception of asthma control by patients: Results of a survey in 5 European countries. Eur Respir J, 30 (suppl):1590, 2007.

4. Bradley E. Chipps, Inhaled corticosteroid therapy for patients with persistent asthma: Learnings from studies of inhaled budesonide. Allergy Asthma Proc, 30: 217-228, 2009;

5. Humbert M., The right tools at the right time, Chest, 130/1, July 2006, suppl.29S.

6. Busse WW., Pedersen S., Pauwels RA. et al. The inhaled sterois treatment as regular therapy in early asthma (START) study 5-year follou-up: effectiveness of early intervention with budesonide in mild persistent asthma. J Allergy Clin Immunol 2008; 121:1167-1174.

7. Pauwels RA, Pedersen S, Busse WW, et al. Early intervention with budesonide in mild persistent asthma: A randomised, double-blind trial. Lancet 361:1071-1076, 2003.

8. The Childhood Asthma Management Program Research Group. Longterm effects of budesonide or nedocromil in children with asthma. $\mathrm{N}$ Engl J Med 343:1054 -1063, 2000

9. Bisgaard H, Hermansen MN, Loland L, et al. Intermittent inhaled corticosteroids in infants with episodic wheezing. N Engl J Med 354:1998 -2005, 2006

10. Boushey HA, Sorkness CA, King TS, et al. Daily versus asneeded corticosteroids for mild persistent asthma. N Engl J Med 352:1519-1528, 2005.

11. O'Byrne PM, Barnes PJ, Rodriguez-Roisin R, et al. Low dose inhaled budesonide and formoterol in mild persistent asthma: The OPTIMA randomized trial. Am J Respir Crit Care Med 164:1392-1397, 2001.

\section{INHALED BUDESONIDE IN THE TREATMENT OF ASTHMA: LESSONS OF PHARMACOLOGICAL STUDIES}

\section{LAIMUTÉ VAIDELIENE \\ DEPARTMENT OF CHILDREN DISEASES LUHS MA}

Keywords: persistent asthma, inhaled corticosteroids, budesonide, combination therapy, safety of treatment.

Summary. Inhaled corticosteroids (ICS) are the preferred medications for long-term asthma therapy. The new studies with ICS budesonide provide interesting information, which supplement current asthma guidelines. The data of 3-year double-blind START (inhaled Steroid Treatment As Regular Therapy) study showed, that early treatment with inhaled budesonide improves airway impairment and reduces the future risk of severe exacerbations in adults and children with newly diagnosed and previously untreated bronchial asthma. Unfortunately, the impact of early ICS treatment on long-term changes in lung function has not been proven. CAMP study (Childhood Asthma Management Program) also confirmed that ICS treatment does not affect the progression of asthma. Nevertheless, the contribution of the CAMP study into asthma treatment guidelines is important, because it confirms the need for continuous treatment with ICS in order to improve asthma control even with no influence on natural course of the disease.

Asthmatic patients often avoid taking ICS for a long time. The most common reason - the worry of side effects. That's why researches are looking for ways to minimize side effects and make treatment more comfortable. The START study confirmed the efficacy and safety of using budesonide once daily. The OPTIMA (Oxis and Pulmicort Turbuhaler in the Management of Asthma) and FACET (Formoterol Corticosteroids and Establishing Therapy) study showed the efficacy and safety of combined therapy for moderate to severe asthma treatment. Taken together, these studies have supported the daily ICS treatment for mild to moderate asthma, recommend the early ICS treatment and introduce the indications of combined therapy.
12. Pauwels RA, Lofdahl C-G, Postma DS, et al. Effect of inhaled formoterol and budesonide on exacerbations of asthma. N Engl J Med 337:1405-1411, 1997.

13. Agertoft $L$, and Pedersen S. Effects of long-term treatment with an inhaled corticosteroid on growth and pulmonary function in asthmatic children. Respir Med 88:373-381, 1994.

14. Selroos $\mathrm{O}$, Pietinalho $A$, Lo" froos $A-B$, and Riska $H$. Effect of early vs late intervention with inhaled corticosteroids in asthma. Chest 108:1228 -1234, 1995.

15. The Childhood Asthma Management Program Research Group. Longterm effects of budesonide or nedocromil in children with asthma. $\mathrm{N}$ Engl J Med 343:1054-1063, 2000.

16. Masoli $M$, Whatherall $M$, Holt $S$ et al. Budesonide once versus twice-daily abministration: mat-analysis; Respiratology 2004, 9: 528-534.

17. T.H.Self, R.M.Sameri, Efficacy of inhaled corticosteroids administered once daily for asthma, Am J Manag Care 2002; 9:91-99.

18. R.Brattsand, A.Miller-Larsson, The role of intracellular esterification in budesonide once-daily dosing and airway selectivity, Clinical therapeutics, 2003, Vol 25, suppl.C: C28-C41.

19. L.Thorsson, A.Kallen. A randomized controlled assessment of the systemic activivty of budesonide when given once or twice daily via turbuhaler, Eur J Clin Pharmacol, 2000, 56: 207-210.

20. Pauwels RA, Pedersen S, Busse WW et al. Early intervention with budesonide in mild persistent asthma: a randomised, dubble-blind trial. Lancet 2003, 361:1071-1076.

21. Agertoft $L$, and Pedersen $S$. Effect of long-term treatment with inhaled budesonide on adult height in children with asthma. N Engl J Med 343:1064 -1069, 2000.

22. T. H. Self, and R. M. Sameri. Efficacy of Inhaled Corticosteroids Administered Once Daily for Asthma; Am J Manag Care 2002;9:91-99.

23. Boushey HA, Sorkness CA, King TS et al. Regular vs. intermittent controller therapy for mild persistent asthma. New England Journal of Medicine 2005; 352:1519-1528. 